\title{
Hard lessons learned: delivering usability in IT projects
}

\author{
Krzysztof Redlarski, Paweł Weichbroth \\ Gdansk University of Technology \\ Faculty of Management and Economics Gdansk, Poland \\ Department of Applied Informatics in Management \\ ul. Narutowicza 11/12, 80-233 Gdańsk, Poland; \\ krzysztof.redlarski, pawel.weichbroth@zie.pg.gda.pl
}

\begin{abstract}
Effective project management requires the development of a realistic plan which aims to ensure the success of the project and ultimately deliver a high quality product to customers. However, experience shows that the majority of software vendors managing projects suffer from numerous problems to provide usability in IT solutions and complete a project in a given time with success. In this paper we discuss, analyze and synthesize the outcomes of a study conducted among IT firms in Poland. As a result, we have identified eight stimulants and three non-stimulants that affect the usability of software products, which later were stratified into three levels. Finally, we outline some of the lessons learned, summarized and expressed as a set of eleven goal-oriented rules.
\end{abstract}

\section{INTRODUCTION}

$\mathrm{P}$ ROJECT management is now one of the fastest growing areas of science, and its development and continuous improvement is sure to be a long-term upto-date research topic. Many firms, during the realization of new IT projects, come across problems with their completion in line with the starting assumptions (i.e. budget, scope and schedule). Strong competition on the market may force them to make difficult decisions to optimize costs. Thus, they aim to find more effective methods of project management which allow them to increase project effectiveness. On the other hand, they look for adequate methods to manage a given project, best suited to its specific needs. However, in practice they have to face many different kinds of problems and obstacles, associated with the usability of the developed product, which directly translates into the success of the entire project. Evidently, a low-end usability product, as a whole, will be perceived as lowquality by its customers.

In this paper, we present and discuss the results obtained from a survey conducted among IT firms located across Poland. Our research includes the main findings of the survey, conducted among project managers, and an analysis of project documentation. We have identified, and later described, the factors (stimulants and non-stimulants) that affect the quality of software products in selected IT projects. In the end, we outline a set of eleven goal-oriented rules as a guideline for software vendors, regarding prousability organization and cooperation with end-users.

\section{IT PRODUCT LIFE CYCLE}

The dynamic pace of change and the development of the IT society bring about numerous problems related to the choice of effective methods of project management, as well as their use and interaction with IT products. Taking appropriate action in the early stages of the development of IT products and services plays a significant role in effective product management (Fig. 1).

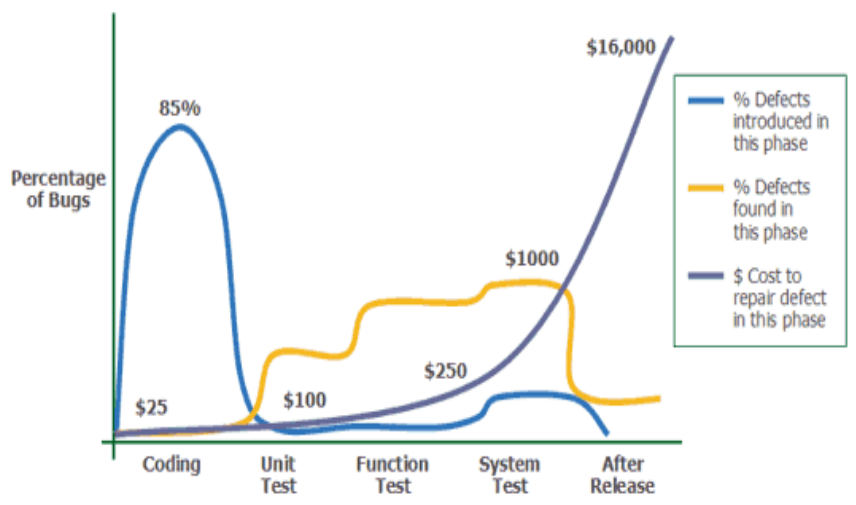

Fig. 1. Cost of the removal of defects implemented in stages of an IT project [1].

Defects implemented in the product in its initial stage of development are particularly costly from the perspective of the product life cycle. They may lead to the eventual failure of the entire project if their number exceeds permissible limits. Hence, it is particularly important to start the process of product quality provision at the earliest possible stage of any IT project.

\section{The Development Of IT Project Management}

The awareness of business decision-makers related to IT product development for end-users is constantly changing. Until the 1980s developers were only focused on software design and perspectives, entirely excluding end-users from the development process. Fortunately, from the early 80s till now, the end-user role has changed. The software vendors have realized that a user-oriented approach can advance product quality on a higher level. In such a way, end-users gradually began to be actively involved in projects, and their 
importance over the years successively increased [2]. Among others, the so-called "human factor" has become an important and relevant element in ensuring high usability of the final product. To put it simple, the problem was to ensure efficiency, effectiveness and satisfaction with everyday use. On the other hand, as a result of a lack of acceptance on the part of the end-users, the sales value of new products can significantly fall, along with the profit of the software vendor.

A user-oriented approach is reflected in changes in both the technology of IT product development, as well as in the methodology of IT project management. Currently, one can particularly observe an intensive usage of soft approaches in project management. For example, the Agile manifesto states that "our highest priority is to satisfy the customer through early and continuous delivery of valuable software". In our opinion, the customer is all different kinds of users, with respect to such values as trust and transparency in communication facility. In turn, in literature of HumanComputer Interaction (HCI), one can distinguish an approach that addresses user-oriented design, defined as User Centered Design (UCD). This approach is characterized by active user participation in the whole design process (analogously to Agile), whilst putting the biggest emphasis on the fulfillment of the requirements and needs of the expected users. However, on the one hand, the goal is to close a project within a given time and budget, while, on the other hand, to deliver a product with high usability. In such a case, an impartial and tenable compromise between each project stakeholder group is a must.

The attempt to identify the factors affecting the provision of high product usability, undertaken in this analysis, is particularly important, because the correct identification of these factors allows us to determine not only the changes taking place in current developments in IT projects, but also to indicate the relationship occurring between selected factors and stakeholder groups.

\section{USABILITY FACTORS}

We undertook both quantitative and qualitative research among five IT firms:

- Infovide-Matrix JSC (IVMX), a company which, according to the IDC report [3], is in the top 10 IT services companies in Poland, with revenues of USD 56.12 million, and employing up to 500 people; the company specializes in consulting, developing and deploying product solutions and technologies in the IT area;

- Aiton Caldwell JSC, a firm specializing in providing SaaS services (Software as a Service), based on remote software sharing via the Internet. The leader of the Polish market of hosted telecommunications services for SMEs and individual clients. The company employs about 50 people, and has about $40 \%$ of the Polish market share of VoIP (Voice over Internet Protocol);
- Kolibro LLC, a company specializing in consulting and deploying internal communication management systems, i.e. corporate intranet portals and dedicated applications for business process management. The company employs about 40 people, and has mainly used Microsoft SharePoint technology and Enterprise Project Management;

- One2tribe $L L C$, a firm specializing mainly in game development for mobile devices. It has, in its portfolio, a number of applications used in popular social networks for marketing purposes. The company employs about 40 people and has been present on the market for eight years;

- Webstruments GP, a firm specializing in the development and implementation of Internet and intranet applications. The company employs about 10 people and has been in business for 7 years, having a portfolio of very interesting projects for major firms, mainly from the public sector.

We purposely selected miscellaneous firms to examine, offering a diverse range of IT products, varying in the total number of employees, annual income, scale of operations and duration of business activity. In fact, the study included the largest IT companies in Poland, which have vast experience and resources involved in projects (taking into account workforce, materials and costs), but also microenterprises, which often equally effectively compete in the market with the biggest market participants. The major goal of the study was to identify the factors affecting the assurance of usability in IT projects, and to assess their impact on the final success of a given project. The study has been divided into two parts:

- The first part was to conduct interviews with project managers, who, whilst sharing their insights, would point to the factors which, in their opinion, influence product usability and the final success of a project.

- The second part was to analyze the documentation of a given project, which described how the project was realized, and indicated the methods and measures applied in order to assure product usability by the personnel responsible for the project.

Next, the identified factors were examined, using an electronic questionnaire in which respondents answered the following questions:

- In your opinion, what was the product usability like? The answer was represented by a 5-point quality scale (very poor, poor, average, good, and very good), where 1 stood for very poor quality, and 5 for very good quality.

- In your opinion, did the project end in success? The answer was represented by a 5-point quality scale (total success, partial success, hard to say, partial failure, and total failure), where 1 stood for total failure of the project, and 5 meant that the project was totally successful. The study was conducted on a group of 30 respondents (participants of IT projects).

The obtained results allowed factors from the first part of the evaluation and the relationship between them to be verified, and juxtaposed with their usability in IT projects. 
Factors with a positive impact (stimulants) on product usability in IT projects are:

- $s_{1}$ : product specification, is a set of documented requirements to be satisfied by the software product;

- $s_{2}$ : user participation, refers to the assignments, activities and behaviors that a user (human) performs during the product development process; these can take a variety of forms: direct (individual action) or indirect (represented by others), local (physical attendance) or remote (physical non-attendance), formal (using legal agreements, documented and obliged) or informal (through informal relationships, discussions, and tasks), performed alone or in collaboration with others (in groups or teams), moderated (driven by other individuals) or liberated.

- $s_{3}$ : project analysis, is a retrospective inspection of the finished project;

- $s_{4}$ : project team size, is the total number of hired staff, assigned to perform a particular set of tasks;

- $s_{5}$ : project team experience, is the total number of similar projects finished by the assigned group of people;

- $s_{6}$ : project team knowledge, is the collective, tacit and incorporeal expertise in a specific domain, demonstrated by the assigned group of people;

- $s_{7}$ : project manager experience, is the ability to manage and mitigate risks, and skills gathered in using risk management methods in previous projects;

- $s_{8}$ : project manager knowledge, reflects the mastery of domain expertise in project management as applied to a particular field or multiple fields, which brings natural authority and solid strategic insight.

On the other hand, we distinguished three factors with a negative impact (non-stimulants) on product usability in IT projects, including:

- $d_{1}$ : project innovativeness, is originality by virtue of introducing a new software product (newness to the developing firm);

- $d_{2}$ : project implementation method, reflects the assumptions, principles and best practices that are used in the software product life cycle.

- $d_{3}$ : project outsourcing, is the presence of external services hired in the project to perform particular tasks.

In addition, we distinguish three separate groups of factors, embodied in three dimensions named, respectively from top to bottom: project, team and project manager (table below).

TABLE I.

THREE Dimensions of UsABILITY FACTORS

\begin{tabular}{|r|c|c|}
\hline \multicolumn{1}{|c|}{ level } & stimulants & non-stimulants \\
\hline project & $\mathrm{s}_{1}, \mathrm{~s}_{2}, \mathrm{~s}_{3}$ & $\mathrm{~d}_{1}, \mathrm{~d}_{2}, \mathrm{~d}_{3}$ \\
\hline team & $\mathrm{s}_{4}, \mathrm{~s}_{5}, \mathrm{~s}_{6}$ & - \\
\hline project manager & $\mathrm{s}_{7}, \mathrm{~s}_{8}$ & - \\
\hline
\end{tabular}

Each individual factor was assigned to a distinct level and each is subsequently represented by a goal-oriented rule in the next section. The project level is the most general and is the only one to have all three non-stimulants assigned as well as the first three stimulants.

The project team and the project manager experience $\left(s_{5}\right.$ and $s_{7}$ ) are particularly important to ensure high project usability. It is also recommended to carry out a so-called post-project analysis after completion of a project. This allows usability errors to be significantly eliminated in subsequent projects. The analysis of the projects surveyed also indicated that a certain level of formalization of the project documentation favored ensuring high usability in a project.

Among the non-stimulants that could negatively affect product usability in IT projects, project innovativeness $\left(d_{1}\right)$ was highlighted. This factor greatly conditioned the participation of end-users in a project. Firms that developed projects of a rather reproductive nature (and thus largely repetitive), would substantially, or even entirely, resign from user participation in a project, thereby aiming to reduce the cost of the entire project. In this case, the risks associated with the failure to provide usability were attributed to the project manager or the whole company responsible for the project. The analysis of the methods used in the surveyed IT projects indicated that there is no direct relationship between one method of project implementation (classic, agile, informal), and the usability of a product. A project which ended in complete success would primarily use informal methods of project management, which combined two main approaches used in project management: the classic and the agile. Moreover, project outsourcing (partial or full range), proved to be a factor negatively influencing product usability. Companies carrying out projects based on the services of external companies fared far worse compared to companies independently pursuing projects.

Therefore, analyzing the development of project management methodologies (see par. 2), it should be stated that there is a continuous tendency to increase the active participation of end-users in projects. However, despite the fact of the increased importance of their participation [4], practice among businesses can be seen to limit the participation of users in selected types of projects. This applies mainly to projects where the product being developed is repetitive and imitative. The active participation of the user in a project corresponds to the necessity to increase the budget of the project, since their presence increases the total costs of the project. Hence, companies willing to increase the chances of a project being realized, and increase the probability of acquiring new customers, deliberately restrict user participation in their projects. Reducing the costs associated with user involvement in a project is, in fact, a significant part of the project budget. The experience of those responsible for the project is, therefore, particularly important for ensuring product usability. 


\section{LESSONS LEARNED}

Rule no. 1 states that the higher the degree of documentation formalization, then the higher the usability and quality of the product being developed. In other words, if you and your client pay more attention to detail, use formal specifications and modeling languages, and share the same dictionary, then the product will demonstrate perceivable values to its users concerning accuracy, efficiency, and satisfaction.

In current practices of usability testing we observed four prototype methods: thinking-aloud, subjective ratings, history files and eye-tracking. The major goal of usability testing is to identify and eliminate obscure problems with the user interface. Rule no. 2 states that the higher the user participation in the life-cycle of software design, then the higher the usability and quality of the product being developed. An important step in addressing these issues is the recent effort to develop a better measure of user participation, constructed by combining different methods.

The post-project analysis documents the results of conducting a deep and broad project assessment from its kickoff to finalization. Rule no. 3 states that the higher the degree of comprehensive post-project analysis, then the less expense and risk together with higher usability are expected in future solutions. A unified analysis should capture successes and failures, challenges and threats, in such areas like: planning, resources, scheduling, development and design, testing, communication, team and organization, solutions and tools.

On the team level we identified three stimulants that concern its size, experience and knowledge. Rule no. 4 states that a bigger project team size boosts a richer essence in knowledge flow between its members and engages more experience and skills, which together move toward higher usability of the product being developed. We also have to keep in mind an adequate arrangement of members of a goal-oriented team.

Satisfaction (subjectively pleasing) is one of Nielsen's five usability attributes, especially important in home computing environments (e.g. video games) where entertainment value comes first, before compatibility, efficiency and reliability that, on the contrary, play a major role in work-related environments. Rule no. 5 states that $a$ more experienced team delivers a technology more preferred by a user, reflected by higher satisfaction of usage.

The ISO 9241 presents a set of usability heuristics which applies to the interaction of people and information systems. In this standard this interaction was called a "dialogue" and the following seven "dialogue principles" were defined: conformity with user expectations, controllability, error tolerance, self-descriptiveness, suitability for individualization, suitability for learning and suitability for the task. They apply to broad and narrow groups of artifacts. The former includes two sets of recommendations: (1) a presentation of information, defined in three main areas such as: organization of information, graphical objects, and coding techniques and (2) user guidance that covers general advice: prompts, feedback, status information, error management and on-line help; the latter includes four sets of recommendations: menu dialogues (such as pop-up, pulldown and text-based menus), command dialogues (command line interface), direct manipulation dialogues and form-filling dialogues. Rule no. 6 states that the higher the knowledge capital of the team developing a particular artifact, then the less ambiguous the dialog between the enduser and the product will be.

One of the most desirable attributes of the project manager is action management, which means acting in such a way that leads to the achievement of expected results through the successful and timely completion of activities and the delivery of the product. Rule no. 7 states that the higher the experience of the project manager, then the more proper usability practices are applied.

Rule no. 8 states that the higher the knowledge demonstrated by the project manager, the more relevant the allocation of time and resources to various means. Regarding rules no. 7 and 8, a skilled project manager should wield knowledge, skills and experience commensurate with the complexity, risk and size of the project.

In a low level innovative project, its specification is often created ad hoc, based on the project manager's experience and knowledge. However, knowing your audience is key to any successful innovation and this is notably true for new products [5]. Rule no. 9 states that higher project innovativeness requires a higher degree of documentation formalization. On the other hand, the level of active user participation in testing usability should always be considered in conjunction with the project innovativeness.

The context specificity of explicit users' requirements does not allow usability to be compared across different IT systems, unless they share comparable functionalities and user interfaces [6]. Rule no. 10 states that the context of use analysis sets up the borders of usability heritage between heterogeneous systems.

Numerous undesirable consequences of IT outsourcing have been reported so far i.e. service debasement, absence of cost reductions, disagreements. Rule no. 11 states that the higher the level of outsourced resources hired in the project then the lower the internal usability of captured know-how.

\section{REFERENCES}

[1] Why Unit Testing? Develop software with confidence. http://www.agitar.com/solutions/why_unit_testing.html

[2] K. Redlarski, The impact of end-user participation in IT projects on product usability, ACM, 2013.

[3] International Data Corporation. http://idcpoland.pl/eng.

[4] E. L. Wagner, and G. Piccoli, Moving beyond user participation to achieve successful IS design. Communications of the ACM, vol. 50 (12), ACM 2007, pp. 51-55.

[5] D. Jelonek, and I. Pawełoszek, Technologie semantyczne w zarządzaniu platforma otwartych innowacji. Informatyka Ekonomiczna, vol. 4(30), 2013, pp. 169-180.

[6] P. Weichbroth, and M. Sikorski, User Interface Prototyping. Techniques, Methods and Tools. Studia Ekonomiczne 2015, 184-198. 